\title{
Bladder cancer risk associated with genotypic polymorphism of the matrix metalloproteinase-1 and 7 in North Indian population
}

\author{
Priyanka Srivastava, Ruchika Gangwar, Rakesh Kapoor and Rama D. Mittal* \\ Department of Urology and Renal Transplantation, Sanjay Gandhi Post Graduate Institute of Medical Sciences, \\ Lucknow, Uttar Pradesh, India
}

\begin{abstract}
Matrix metalloproteinases (MMPs) contribute to tumor invasion and microenvironment, hence are associated with bladder cancer risk. We therefore, tested whether polymorphisms in MMP genes modify the risk of bladder cancer (BC) and whether smoke exposure modifies this risk.

Genotyping was performed in $200 \mathrm{BC}$ patients and 200 controls by polymerase chain reaction-restriction fragment length polymorphism (PCR-RFLP). MMP1-1607 2G/2G and MMP7-181 GG genotype were associated with increased risk of BC ( $p<$ 0.001; OR, 3.04; 95\% CI- 1.71-5.39 and p, 0.005; OR, 2.38; 95\% CI- 1.30-4.34) respectively. Smokers in BC patients showed significant increased risk for the same SNPs (p, 0.006; OR, 3.20; 95\% CI- 1.40-7.31 and p, 0.009; OR, 2.85; 95\% CI- 1.30-6.23 respectively). Haplotype analysis too revealed significant association with $\mathrm{G} / 2 \mathrm{G}$ of $M M P 1-519-1607$ ( $p<0.001 ; \mathrm{OR}, 2.62 ; 95 \%$ CI- 1.68-4.09). The $2 \mathrm{G}$ allele carrier $(1 \mathrm{G} / 2 \mathrm{G}+2 \mathrm{G} / 2 \mathrm{G})$ of $M M P 1-1607$ showed a protective effect and high recurrence free survival in Bacillus Calmette-Guérin (BCG) treated non muscle invasive BC (NMIBC) patients (log rank p, 0.030). Our data suggested that $M M P 1-16072 \mathrm{G}$ and $M M P 7-181 \mathrm{G}$ allele were associated with high risk of $\mathrm{BC}$, which was quite evident amongst smokers too. BCG treated NMIBC patients reflected protective effect for $2 \mathrm{G}$ allele carrier $(1 \mathrm{G} / 2 \mathrm{G}+2 \mathrm{G} / 2 \mathrm{G})$ of $M M P 1-1607$. This study provided new support for the association of MMP1-1607 and MMP7-181 in bladder cancer development, the tumorigenic effect of which was observed to be more enhanced in case of tobacco exposure.
\end{abstract}

Keywords: Bacillus Calmette-Guérin, bladder cancer, haplotypes, matrix metalloproteinase, polymorphism, recurrence free survival

\section{Introduction}

Transitional cell carcinoma (TCC) accounts for $90 \%$ of all cases of bladder cancer (BC) and remains as a significant cause of morbidity and death [1]. Most BC (70-80\%) present as non-muscle-invasive papillary tumors which recur frequently (50-80\%), but progress

*Corresponding author: Dr. Rama Devi Mittal, Department of Urology, SGPGIMS, Raebareli Road, Lucknow-226014, India. Tel.: +91 5222668004 8, Ext. 2116; Fax: +91 5222668 017; E-mail: ramamittal@gmail.com; rmittal@sgpgi.ac.in. less often (5-30\%) to invade bladder muscle wall. By contrast, the remaining $20-30 \%$ of $\mathrm{BC}$ is aggressive muscle-invasive tumors that have a much higher risk of metastasis, despite radical treatment [2].

Over the last three decades, intravesical immunotherapy with the biological response modifier Bacillus Calmette-Guérin (BCG) has been established as the most effective adjuvant treatment for preventing local recurrences and tumor progression following transurethral resection of non-muscle invasive BC [3], however, the response rate for BCG treatment is only $60 \%$ to $70 \%$. A large number of clinical trials have 
established a major role for BCG immunotherapy in urological oncology.

Although tobacco smoke and other environmental pollutants are responsible for more than $80-90 \%$ of the cases in men [4]. It is well established that less than $10-15 \%$ of smokers develop BC, indicating that other factors could also be responsible for the development of $\mathrm{BC}$ [5]. Polymorphisms represent natural variations of the genetic code in the population. The most common polymorphisms are single-nucleotide polymorphisms (SNPs). Polymorphisms in the promoter region of a gene, such as the $2 \mathrm{G}$ allele of MMP1 -1607, and MMP$7-181 \mathrm{~A} / \mathrm{G}$ polymorphism has been shown to be associated with malignant diseases [6].

The matrix metalloproteinases MMPs are implicated in a number of pathological processes such as invasion and metastasis of tumor cells. Polymorphisms in the regulatory regions of MMPs have been associated with changes in the expression level of these genes in different human diseases $[7,8]$. In fact, the $-16071 \mathrm{G} / 2 \mathrm{G}$ polymorphism in the promoter region of $M M P l$ creates an Ets binding site which increases the promoter activity of this gene [9]. Thus, the $2 \mathrm{G}$ allele of $M M P 1$ has significantly higher transcriptional activity than the $1 \mathrm{G}$ allele and has been associated with an increased risk of common cancers, including oral, colorectal, renal and head and neck [10,11]. Furthermore, in colorectal and ovarian cancer, the presence of the $2 \mathrm{G}$ allele in the $M M P 1$ gene was significantly associated with poorer survival of patients with cancer $[12,13]$.

Matrix metalloproteinase-7 (MMP-7) is a small secreted proteolytic enzyme with broad substrate specificity [14]. Its expression has been shown to be associated with tumor invasion, metastasis and survival for a variety of cancers. The gene encoding $M M P-7$ is localized on chromosome $11 \mathrm{q} 21-\mathrm{q} 22$. One of the $M M P-7-181 \mathrm{~A} / \mathrm{G}$ polymorphism has been shown to be associated with malignant diseases [15].

Given the genetic complexity of bladder cancer, individual polymorphisms are likely to have a modest effect on risk. However, examining multiple polymorphisms within biologically relevant pathways may reveal subgroups of individuals who are at significantly elevated risk for this disease. Besides the promoters of the $M M P-1$ and MMP-7 genes contain polymorphism and have allele-specific effects on the regulation of MMP gene transcription and are associated with development of some cancers.

In this study, we identified the possible association of $M M P-1-1607$ 1G/2G, MMP-1 -519 A/G and MMP$7-181 \mathrm{~A} / \mathrm{G}$ genes in BC patients and healthy controls from North India with the risk of bladder cancer and to investigate the possible modulating effect of smoking on these associations.

\section{Material and methods}

\subsection{Study subjects}

The bladder cancer patients in this analysis were enrolled from an on-going case-control study of bladder cancer, which started patient recruitment in 2005. All enrolled patients were incident cases of histologically confirmed invasive or superficial bladder cancer and were recruited from the Urology department at Sanjay Gandhi Postgraduate Institute of Medical Sciences, a tertiary care center, from May 2005 to June 2009. A total of 200 patients with histologically confirmed transitional urothelial BC (mean age 58.5 years; 175 men and 25 women) were recruited for the study. Those with previous history of other cancer, cancer metastasized to the bladder from another origin, and previous radiotherapy was excluded. Healthy and genetically unrelated individuals visiting the hospital for a routine checkup or health awareness camps and hospital employees were recruited as the controls $(n=200)$. All the controls were age and sex matched with similar ethnicity and had no evidence of malignancy or chronic disease. The mean age of the controls was 56.8 years, and $\mathrm{M}$ : F ratio as 179:21. The disproportionate ratio between male and female bladder cancer in our population could be largely due to increased prevalence in case of males (3:1). Secondly due to social taboos females avoid visiting hospitals/clinics. The participation rate was $100 \%$, and blood samples were available for all subjects. Ethnicity was based on self-report and categorized as North Indian. An epidemiologic questionnaire was designed for study participants to collect data on demographic characteristics, smoking history, occupation history, and other lifestyle factors were employed. At the end of the interview, a 5-ml blood sample was drawn into coded tubes.

Informed and written consent was taken from all subjects when interviewing for the demographic details and blood sample collection. The Ethical Review Board of the Institute approved the study.

\subsection{Epidemiology data collection}

The demographic details were obtained by interviewing each individual in cases and controls. The response 
Table 1

Demographical details of urinary bladder cancer patients and healthy controls

\begin{tabular}{|c|c|c|c|}
\hline Variable & $\begin{array}{c}\text { Cases (200) } \\
\mathrm{N}(\%) \\
\end{array}$ & $\begin{array}{c}\text { Controls (200) } \\
\mathrm{n}(\%) \\
\end{array}$ & $\begin{array}{c}\text { Chi-square- } \\
\text { value }\end{array}$ \\
\hline \multicolumn{4}{|l|}{ Sex } \\
\hline Female & $25(12.5)$ & $21(10.5)$ & 0.531 \\
\hline Male & $175(87.5)$ & $179(89.5)$ & \\
\hline \multicolumn{4}{|l|}{ Age (Years) } \\
\hline Mean age \pm SD & $58.5 \pm 12.4$ & 56. $8 \pm 10.8$ & $0.117^{\$}$ \\
\hline \multicolumn{4}{|l|}{ Smoking* } \\
\hline Never Smokers & $78(50)$ & $155(77.5)$ & 0.001 \\
\hline Smokers & $78(50)$ & $45(22.5)$ & \\
\hline \multicolumn{4}{|l|}{ Tumor number* } \\
\hline Single & $115(60.8)$ & - & - \\
\hline Multiple & $74(39.2)$ & - & \\
\hline \multicolumn{4}{|l|}{ Tumor Size $(\mathrm{cm})^{*}$} \\
\hline$<1$ & $35(24.3)$ & - & - \\
\hline $1-3$ & $73(50.7)$ & - & \\
\hline$>3$ & $36(25.0)$ & - & \\
\hline \multicolumn{4}{|l|}{ Stage } \\
\hline $\mathrm{Ta}$ & $64(32.0)$ & - & - \\
\hline $\mathrm{T} 1$ & $85(42.5)$ & - & \\
\hline $\mathrm{T} 2$ & $51(25.5)$ & - & \\
\hline \multicolumn{4}{|l|}{ Grade } \\
\hline G1 & $67(33.5)$ & - & - \\
\hline G2 & $43(21.5)$ & - & \\
\hline G3 & $90(45.0)$ & - & \\
\hline \multicolumn{4}{|l|}{ Intravesical Therapy } \\
\hline Non treated & $71(47.7)$ & - & - \\
\hline BCG Induction (BCG i+m) & $78(52.3)$ & - & \\
\hline \multicolumn{4}{|l|}{ Event } \\
\hline Recurrence & $65(43.9)$ & - & - \\
\hline Non-Recurrence & $83(56.1)$ & - & \\
\hline
\end{tabular}

$\$$ Student t-test was used to determine the p-value

*The sum could not add up to the total due to some missing values.

rate for the interview was $75 \%$ for the subjects. Individuals who smoked once a day for more than 5 years were defined as smokers. The individuals who had never smoked in their lifetime were regarded as non smokers. At the conclusion of the interview, a $5 \mathrm{ml}$ of blood sample was drawn into coded vials.

\subsection{Clinical data collection}

The demographic and clinical characteristics of the patients are presented in Table 1 . The clinical information about tumor size, number, stage and tumor grade, intravesical therapy and dates of recurrence, chemotherapy, radical cystectomy and pathological findings at cystectomy were provided by the UroOncologist in our department. The tumor stages were classified as per American Joint Committee on Cancer's TNM staging system [16]. Of the 200 total patients enrolled in the study, 149 patients had non muscle invasive bladder cancer (NMIBC) while the rest 51 had muscle invasive bladder cancer (MIBC). Patients with
NMIBC at high risk (high grade, multiple and large tumor) were treated with intravesical Bacillus CalmetteGuerin (BCG) $(n=78)$. The patients with NMI cancer of low risk (low grade and single small tumor) were kept on cystoscopic surveillance and considered as Non BCG patients. Subsequently, all the patients were examined by cystoscopy after every 3 months in first and second years and later at six monthly intervals as long as there was no tumor recurrence. BCG treatment consisted of 6 weekly instillation induction BCG $(n=78)$. Since the number of patients receiving maintenance BCG was too low, we did not categorize the patients according to BCG regime for statistical analysis. The end point of study included tumor recurrence, defined as a newly found bladder tumor following a previous negative follow-up cystoscopy, or end of study time (60 months). Patients with invasive $\mathrm{BC}(n=51)$ were treated with radical cystectomy with or without adjuvant chemotherapy, which included cisplatin, gemcitabine followed by periodical cystoscopy. Blood sample was collected in EDTA from all subjects 


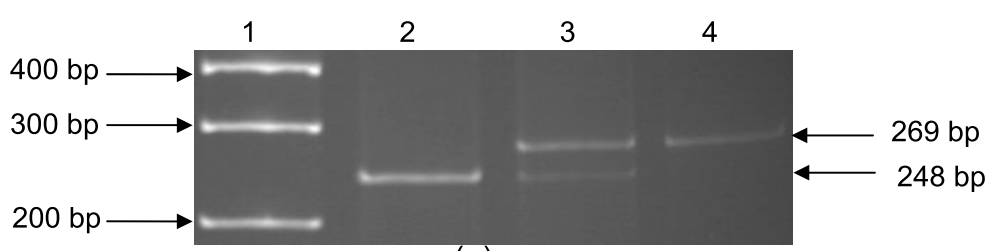

(a)

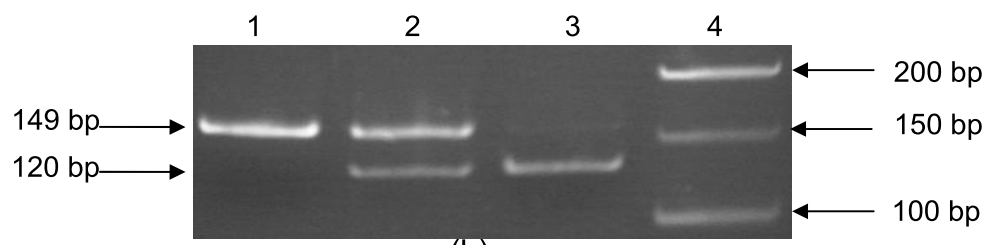

(b)

Fig. 1. (a). Representative Gel picture of $M M P 1-1607$ (1G/2G) polymorphism. Lane 1: 100bp ladder, Lane 2: wild (1G/1G), Lane 3: hetero $(1 \mathrm{G} / 2 \mathrm{G})$, Lane 4: variant $(2 \mathrm{G} / 2 \mathrm{G})(\mathrm{b})$. Representative Gel picture of $M M P 7-181(\mathrm{~A} / \mathrm{G})$ polymorphism. Lane 1: wild (AA), Lane 2: hetero (AG), Lane 3: variant (GG), Lane 4: 50bp ladder.

for genotyping at the time of enrollment and stored at $-70^{\circ} \mathrm{C}$.

\subsection{Genotyping}

Genomic DNA was extracted from peripheral blood lymphocytes by salting out method [17]. Polymorphisms in MMP1 -1607 1G/2G, -519 A/G and MMP7 $-181 \mathrm{~A} / \mathrm{G}$ were analyzed using polymerase chain reaction-restriction fragment length polymorphism, as shown in Fig. 1(a), 1(b) respectively. Details of the primers and cycle conditions for $M M P 1$ and $M M P 7$ have been previously described [17,18]. Positive and negative controls were used in each genotyping assay, and $10 \%$ of the samples were randomly selected and run in duplicates with $100 \%$ concordance. The results were reproducible with no discrepancy in genotyping.

\subsection{Statistical analysis}

The power of the study was calculated using Quanto software, version 1.0 (available from: http://hydra.usc. edu/gxe) with input of following variables: casecontrol study design, significance level (alpha) $>0.05$ ( 2 sided), model of inheritance was log additive, allele frequency was 0.28 , and the genetic effect for odds ratio (OR) was 1.65 or greater. The present study achieved $80 \%$ of the statistical power for the minor allele of MMP1 519A/G, which exhibited the lowest allele frequency among the 3 polymorphisms. The goodnessof-fit chi square test was used to analyze any deviation from the Hardy-Weinberg equilibrium in controls. A binary logistic regression model was used to esti- mate the risk as the OR at the $95 \%$ confidence interval. Haplotypes of each individual consisting of 2 single nucleotide polymorphisms (SNP) in MMP1 was constructed, and the maximal likelihood haplotype frequencies were estimated using the expectationmaximization algorithm using the Arlequin program, version 2.000. Bonferroni's correction was applied in case of multiple comparisons using the formula $p_{c}=p \times n$ ( $P c$ represents corrected value where $\mathrm{n}$ is the number of comparisons performed). The statistical analysis was done using the Statistical Package for Social Sciences software, version 11.5 (SPSS, Chicago, IL), and $P 0.05$ was considered statistically significant.

\section{Results}

\subsection{Characteristics of subjects}

A total of 200 controls and 200 cases were recruited for this study. There was no significant age difference between the cases $(58.5 \pm 12.4$ years $)$ and the controls (56. $8 \pm 10.8$ years) (p, 0.117). The cases had significantly higher percentage of smokers $(50.0 \%)$ than the controls $(22.5 \%)$ ( $p, 0.001)$. The demographic details of the study subjects and clinical characteristics of the patients are presented in Table 1.

\section{2. $M M P 1-16071 G>2 G,-519 A>G, M M P 7$ $-181 A>G$ gene polymorphisms in bladder cancer}

The genotype and allele frequencies of matrix metalloproteinase 1 and 7 gene polymorphism in healthy 
Table 2

$M M P 1-519 \mathrm{~A}>\mathrm{G},-16071 \mathrm{G}>2 \mathrm{G}, M M P 7-181 \mathrm{~A}>\mathrm{G}$ gene polymorphisms in bladder cancer polymorphisms and susceptibility to bladder cancer

\begin{tabular}{|c|c|c|c|c|}
\hline Genotype & $\begin{array}{c}\text { Controls, } \\
\mathrm{n}(\%), \\
(n=200)\end{array}$ & $\begin{array}{c}\text { Cases, } \\
\mathrm{n}(\%), \\
(n=200)\end{array}$ & $\mathrm{p}$ - value & $\begin{array}{c}\text { Age -gender- } \\
\text { smoking adjusted } \\
\text { OR }(95 \% \mathrm{CI})\end{array}$ \\
\hline \multicolumn{5}{|l|}{$M M P 1-519$} \\
\hline AA & $105(52.5)$ & $90(45.0)$ & Ref & Ref \\
\hline AG & $75(37.5)$ & $87(43.5)$ & 0.077 & $1.49(0.95-2.31)$ \\
\hline GG & $20(10.0)$ & $23(11.5)$ & 0.190 & $1.59(0.79-3.20)$ \\
\hline $\mathrm{AG}+\mathrm{GG}$ & $95(47.5)$ & $110(55.0)$ & 0.078 & $1.43(0.96-2.15)$ \\
\hline A allele & $285(71.3)$ & $271(67.7)$ & Ref & \\
\hline $\mathrm{G}$ allele & $115(28.7)$ & $129(32.3)$ & 0.347 & $0.79(0.50-1.27)$ \\
\hline \multicolumn{5}{|l|}{$M M P 1-1607$} \\
\hline $1 \mathrm{G} / 1 \mathrm{G}$ & $53(26.5)$ & $28(14.0)$ & Ref & Ref \\
\hline $1 \mathrm{G} / 2 \mathrm{G}$ & $87(43.5)$ & $75(37.5)$ & 0.127 & $1.55(0.88-2.74)$ \\
\hline $2 \mathrm{G} / 2 \mathrm{G}$ & $60(30.0)$ & $97(48.5)$ & $<0.001$ & $3.04(1.71-5.39)$ \\
\hline$(1 \mathrm{G} / 2 \mathrm{G})+(2 \mathrm{G} / 2 \mathrm{G})$ & $147(73.5)$ & $172(86.0)$ & 0.002 & $2.29(1.37-3.82)$ \\
\hline $1 \mathrm{G}$ allele & $193(48.2)$ & $134(33.5)$ & Ref & \\
\hline $2 \mathrm{G}$ allele & $207(51.8)$ & $266(66.5)$ & $<0.001$ & $2.24(1.47-3.41)$ \\
\hline \multicolumn{5}{|l|}{ MMP7-181 } \\
\hline AA & $73(36.5)$ & $64(32.0)$ & Ref & Ref \\
\hline AG & $97(48.5)$ & $84(42.0)$ & 0.780 & $1.06(0.67-1.70)$ \\
\hline GG & $30(15.0)$ & $52(26.0)$ & 0.005 & $2.38(1.30-4.34)$ \\
\hline$(\mathrm{AG})+(\mathrm{GG})$ & $127(63.5)$ & $136(68.0)$ & 0.198 & $1.32(0.86-2.02)$ \\
\hline A allele & $243(60.7)$ & $212(53.0)$ & Ref & \\
\hline G allele & $157(39.3)$ & $188(47.0)$ & 0.699 & $0.90(0.52-1.53)$ \\
\hline
\end{tabular}

Table 3

Association of $M M P 1-519 \mathrm{~A}>\mathrm{G},-16091 \mathrm{G}>2 \mathrm{G}, M M P 7-181 \mathrm{~A}>\mathrm{G}$ polymorphisms with tumor grade/stage categories of $\mathrm{BC}$ patients

\begin{tabular}{|c|c|c|c|c|c|c|c|}
\hline & $\begin{array}{c}\text { (a) } \\
\mathrm{n}(\%)\end{array}$ & $\begin{array}{c}\text { (b) } \\
\mathrm{n}(\%)\end{array}$ & $\begin{array}{c}(\mathrm{c}) \\
\mathrm{n}(\%)\end{array}$ & $\begin{array}{c}\text { p-value } \\
(a-b)\end{array}$ & $\mathrm{OR}, 95 \% \mathrm{CI}^{*}$ & $\begin{array}{c}\text { p-value } \\
(\mathrm{a}-\mathrm{c})\end{array}$ & OR, $95 \% \mathrm{CI}^{*}$ \\
\hline$M M P 1-519$ & $\mathrm{AA}$ & $\mathrm{AG}$ & GG & \multicolumn{4}{|c|}{ - Reference -} \\
\hline TaG1 & $15(40.5)$ & $18(48.6)$ & $4(10.9)$ & & & & \\
\hline TaG2-3,T1G1-3 & $52(46.8)$ & $45(40.5)$ & $14(12.7)$ & 0.263 & $0.61(0.26-1.44)$ & 0.994 & $1.00(0.27-3.78)$ \\
\hline $\mathrm{T} 2+$ & $23(45.1)$ & $23(45.1)$ & $6(9.8)$ & 0.393 & $0.65(0.25-1.72)$ & 0.506 & $0.57(0.10-3.03)$ \\
\hline$M M P 1-1607$ & $1 \mathrm{G} / 1 \mathrm{G}$ & $1 \mathrm{G} / 2 \mathrm{G}$ & $2 \mathrm{G} / 2 \mathrm{G}$ & & & & \\
\hline TaG1 & $3(8.2)$ & $16(43.2)$ & $18(48.6)$ & & \multicolumn{2}{|c|}{ — Reference } & \\
\hline TaG2-3,T1G2-3 & $15(13.6)$ & $44(39.6)$ & $52(46.8)$ & 0.342 & $0.49(0.11-2.12)$ & 0.348 & $0.50(0.11-2.12)$ \\
\hline $\mathrm{T} 2+$ & $10(19.6)$ & $16(29.4)$ & $26(51.0)$ & 0.065 & $0.23(0.05-1.09)$ & 0.154 & $0.34(0.08-1.50)$ \\
\hline$M M P 7-181$ & AA & AG & GG & & & & \\
\hline TaG1 & $9(24.4)$ & $14(37.8)$ & $14(37.8)$ & & \multicolumn{2}{|c|}{ — Reference -} & \\
\hline TaG2-3,T1G2-3 & $40(36.0)$ & $45(40.5)$ & $26(23.5)$ & 0.567 & $0.75(0.28-1.99)$ & 0.114 & $0.44(0.16-1.22)$ \\
\hline $\mathrm{T} 2+$ & $15(29.4)$ & $24(47.1)$ & $13(23.5)$ & 0.933 & $0.95(0.30-2.97)$ & 0.244 & $0.49(0.14-1.63)$ \\
\hline
\end{tabular}

*Age, gender, smoking adjusted odds ratio and 95\%CI.

controls and patients with BC are presented in Table 2. The genotype frequency in the controls was in Hardy Weinberg Equilibrium. The variant allele frequency (G) of $M M P 1-519 \mathrm{~A}>\mathrm{G}$ was higher in cases as compared to controls ( $32.3 \%$ vs $28.8 \%$ ). Overall no statistically significant association was observed in $M M P 1$ 519A > G (p, 0.347; OR, 0.79). In MMP1-1607, significant association was observed with $2 \mathrm{G} / 2 \mathrm{G}$ genotype $(p<0.001$; OR, 3.04) which was also evident in case of alleles 2G ( $p<0.001$; OR, 2.24). Therefore, individuals carrying the $2 \mathrm{G}$ allele were at higher risk of developing BC. The variant allele ( $2 \mathrm{G}$ allele) frequency in $M M P 1-1607$ was $51.8 \%$ in controls and $66.5 \%$ in cases. In $M M P 7-181 \mathrm{~A}>\mathrm{G}$, the variant $\mathrm{G}$ allele was $47 \%$ prevalent in cases compared to $39.3 \%$ in controls. The homozygous variant genotype (GG) of $M M P 7-181$ showed 2 folds increased risk with BC patients ( $p=$ 0.005 ; OR, 2.38) which was statistically significant.

\subsection{Association of MMP1 and MMP7 genotypes with tumor stage/grade}

The patients with similar stage but with different grades respond to treatment differently [15]. Hence 
Table 4

Association of $M M P 1$ and $M M P 7$ with smoking status in patients and controls

\begin{tabular}{|c|c|c|c|c|c|c|}
\hline \multirow[t]{2}{*}{ Genotypes } & \multicolumn{2}{|c|}{ Controls } & \multicolumn{2}{|c|}{ Patients } & \multirow{2}{*}{$\begin{array}{c}\text { OR } \\
(95 \% \mathrm{CI})^{*} \\
\text { P value } \\
(\mathrm{a}-\mathrm{c})\end{array}$} & \multirow{2}{*}{$\begin{array}{c}\text { OR } \\
(95 \% \mathrm{CI})^{*}, \\
\text { P value } \\
(\mathrm{b}-\mathrm{d})\end{array}$} \\
\hline & Non smoker ${ }^{\mathrm{a}}$ & Smokers ${ }^{\mathrm{b}}$ & Non smokers ${ }^{\mathrm{c}}$ & Smokers & & \\
\hline \multicolumn{7}{|c|}{$M M P 1-519(\mathrm{~A} / \mathrm{G})$} \\
\hline AA & $80(51.6)$ & $25(55.6)$ & $37(47.4)$ & $29(37.2)$ & Ref & Ref \\
\hline AG & $59(38.1)$ & $16(35.6)$ & $33(42.3)$ & $37(47.4)$ & $\begin{array}{c}1.93 \\
(0.82-4.51) \\
0.129\end{array}$ & $\begin{array}{c}1.50 \\
(0.81-2.77) \\
0.201\end{array}$ \\
\hline GG & $16(10.3)$ & $4(8.8)$ & $8(10.3)$ & $12(15.4)$ & $\begin{array}{c}2.73 \\
(0.73-10.22) \\
0.136\end{array}$ & $\begin{array}{c}1.37 \\
(0.52-3.62) \\
0.529\end{array}$ \\
\hline \multicolumn{7}{|c|}{$M M P 1-1607(1 \mathrm{G} / 2 \mathrm{G})$} \\
\hline $1 \mathrm{G} / 1 \mathrm{G}$ & $42(27.1)$ & $11(24.4)$ & $10(12.8)$ & $15(19.3)$ & Ref & Ref \\
\hline $1 \mathrm{G} / 2 \mathrm{G}$ & $64(41.3)$ & $23(51.2)$ & $31(39.7)$ & $26(33.3)$ & $\begin{array}{c}0.87 \\
(0.32-2.37) \\
0.788\end{array}$ & $\begin{array}{c}1.96 \\
(0.86-4.47) \\
0.110\end{array}$ \\
\hline $2 \mathrm{G} / 2 \mathrm{G}$ & $49(31.6)$ & $11(24.4)$ & $37(47.5)$ & $37(47.4)$ & $\begin{array}{c}2.75 \\
(0.94-8.08) \\
0.065\end{array}$ & $\begin{array}{c}3.20 \\
(1.40-7.31) \\
0.006\end{array}$ \\
\hline \multicolumn{7}{|c|}{$M M P 7-181(\mathrm{~A} / \mathrm{G})$} \\
\hline AA & $55(35.5)$ & $18(40.0)$ & 21(26.9) & $33(42.3)$ & Ref & Ref \\
\hline AG & $74(47.7)$ & $23(51.1)$ & $32(41.0)$ & $29(37.2)$ & $\begin{array}{c}0.84 \\
(0.36-1.98) \\
0.696\end{array}$ & $\begin{array}{c}1.22 \\
(0.63-2.38) \\
0.558\end{array}$ \\
\hline GG & $26(16.8)$ & $4(8.9)$ & $25(32.1)$ & $16(20.5)$ & $\begin{array}{c}2.35 \\
(0.65-8.52) \\
0.194\end{array}$ & $\begin{array}{c}2.85 \\
(1.30-6.23) \\
0.009\end{array}$ \\
\hline
\end{tabular}

*Age, gender adjusted odds ratio and 95\%CI.

we stratified the patients into three categories according to stage/grade [TaG1 (low risk NMIBC), $\mathrm{TaG}_{2,3}+$ $\mathrm{T}_{1} \mathrm{G}_{1-3}$ (High risk NMIBC) and T2+ (muscle invasive)] (Table 3). $\mathrm{TaG}_{1}$ was taken as a reference. No significant association was observed statistically in any of the three polymorphism with the tumor stages.

\subsection{Association of MMP1 and MMP7 genotypes with smoking}

The subjects were grouped as non smokers and smokers in both controls and patients respectively (Table 4). In case of $M M P 1-519$, no significant association was observed. In, MMP1-1607 the variant genotype $2 \mathrm{G} / 2 \mathrm{G}$ was associated with high risk of $\mathrm{BC}$ among smokers ( $p=0.006$; OR, 3.20) and in MMP7, the GG genotype was also significantly associated with high risk of 2 folds among smokers ( $p=0.009$; OR, 2.85) in patients.

\subsection{Association of MMP1 haplotypes with bladder cancer risk}

Haplotype analysis was used to determine the association between the two promoter polymorphism of
MMP1. A-1G was taken as reference. The haplotype results demonstrated that $M M P 1-519-1607 \mathrm{G}-1 \mathrm{G}$ to be associated with 1.7 folds (OR-1.7, 95\%CI- 1.20-2.41, $P c=0.012)$ increased risk in bladder cancer patients. MMP1-519-1607 G-2G (variant alleles of both sites) to be associated with 2.6 folds (OR- 2.62, 95\%- $1.68-$ 4.09, $P c=0.004)$ risk for BC (Table 6).

\subsection{Modulation of genotype variants and outcome after BCG immunotherapy}

To analyze the association of $M M P 1$ and $M M P 7$ gene polymorphisms and risk of recurrence in NMIBC patients, further analysis was restricted to NMIBC patients only ( $n=148$ ). The median follow-up of NMIBC patients was 14 months (3-60 months). We analyzed the association of genotypes and risk of recurrence after BCG immunotherapy. We grouped patients into BCG treated $(n=78)$ and non-treated $(n=$ 70) as these were patients of low grade tumors and did not require BCG immunotherapy. The patients of "BCG group" with heterozygous genotype of MMP11607 were observed to have reduced risk (p, 0.017; HR, 0.28) (Table 5). Similarly the variant allele carrier $1 G+2 G / 2 G+2 G$ was also observed too be at statistical- 
Table 5

Influence of $M M P 1$ and $M M P 7$ gene polymorphisms on the risk of recurrence in BCG treated NMIBC patients

\begin{tabular}{lcccc}
\hline & & BCG & \\
& No & Recurrence & p value & HR (95\%CI) \\
& Recurrence & & & \\
MMP1-519(A/G) & $\mathrm{n}(\%)$ & $\mathrm{n}(\%)$ & & \\
$\mathrm{AA}$ & $18(40.9)$ & $12(35.3)$ & Ref & \\
$\mathrm{GA}$ & $23(52.3)$ & $16(47.1)$ & 0.801 & $0.91(0.42-1.95)$ \\
$\mathrm{GG}$ & $3(6.8)$ & $6(17.6)$ & 0.158 & $2.03(0.76-5.44)$ \\
$\mathrm{GA}+\mathrm{GG}$ & $26(59.1)$ & $22(64.7)$ & 0.834 & $1.08(0.53-2.20)$ \\
$M M P 1-1609(1 \mathrm{G} / 2 \mathrm{G})$ & & & & \\
$1 \mathrm{G} / 1 \mathrm{G}$ & $3(6.8)$ & $7(20.6)$ & Ref & \\
$1 \mathrm{G} / 2 \mathrm{G}$ & $20(45.5)$ & $10(29.4)$ & 0.017 & $0.28(0.10-0.80)$ \\
$2 \mathrm{G} / 2 \mathrm{G}$ & $21(47.7)$ & $17(50.0)$ & 0.129 & $0.480(0.19-1.24)$ \\
$1 \mathrm{G} / 2 \mathrm{G}+2 \mathrm{G} / 2 \mathrm{G}$ & $41(93.2)$ & $27(79.4)$ & 0.039 & $0.39(0.16-0.95)$ \\
$M M P 7-181(\mathrm{~A} / \mathrm{G})$ & & & & \\
$\mathrm{AA}$ & $16(36.4)$ & $10(29.4)$ & Ref & \\
$\mathrm{AG}$ & $15(34.1)$ & $14(41.2)$ & 0.393 & $1.45(0.62-3.38)$ \\
$\mathrm{GG}$ & $13(29.5)$ & $10(29.4)$ & 0.759 & $1.15(0.47-2.84$ \\
$\mathrm{AG}+\mathrm{GG}$ & $28(63.6)$ & $24(70.6)$ & 0.498 & $1.13(0.61-2.81)$ \\
\hline
\end{tabular}

HR, Age, gender and smoking adjusted Hazards Ratio; 95\% CI, Confidence interval.

Table 6

Haplotype analysis of $M M P 1$ gene polymorphisms in bladder cancer patients and healthy controls

\begin{tabular}{lcccc}
\hline & $\begin{array}{c}\text { Controls } \\
\mathrm{n}(\%)\end{array}$ & $\begin{array}{c}\text { Patients } \\
\mathrm{n}(\%)\end{array}$ & OR (95\%CI) & p value \\
\hline MMP1 haplotype $(519 \mathrm{~A} / \mathrm{G}-16071 \mathrm{G} / 2 \mathrm{G})$ & \\
$\mathrm{A}-1 \mathrm{G}$ & $127(31.8)$ & $86(21.4)$ & Ref & Ref \\
A-2G & $66(16.4)$ & $45(11.4)$ & $1.01(0.63-1.61)$ & 0.977 \\
$\mathrm{G}-1 \mathrm{G}$ & $158(39.4)$ & $181(45.2)$ & $1.70(1.20-2.41)$ & 0.003 \\
$\mathrm{G}-2 \mathrm{G}$ & $49(12.4)$ & $88(22.0)$ & $2.62(1.68-4.09)$ & $<0.001$ \\
\hline
\end{tabular}

(Bonferroni corrected P-value) $P c=0.012, \mathrm{Pc} 0.004$

ly reduced risk of $\mathrm{BC}$ ( $p=0.039$; HR, 0.39). Subsequently, Kaplan-Meier analysis showed a higher median recurrence free survival of 54 months of $1 \mathrm{G} / 2 \mathrm{G}+$ $2 \mathrm{G} / 2 \mathrm{G}$ genotype as compared to 34 months for $1 \mathrm{G} / 1 \mathrm{G}$ genotype carrying patients $(\log \operatorname{rank} p=0.030)$ (Fig. 2) in BCG treated patients. None of the other polymorphisms were associated with risk of recurrence free survival.

\section{Discussion}

MMPs are a class of proteases that contribute significantly and uniquely to the tumor microenvironment, which provides the elements needed for advanced tumor growth (i.e., cytokines, loss of contact inhibition, angiogenesis, and invasion [19].

MMPs are essential for tumor cells to penetrate the basement membrane and colonize distant sites. Among MMPs, $M M P-1$ is the most ubiquitously expressed interstitial collagenase, thereby claiming a prominent role in collagen degradation [20]. Clinical research showed the presence of $M M P-1$ in cancer cells, and that $M M P$ 1 expression is associated with a poor prognosis [21]. In the present study we have focused on two promoter polymorphism of MMP1. MMP1 -519 was not associated with $\mathrm{BC}$ risk or with any confounding factors. The other sequence polymorphism of MMP1 -1607 where, the insertion of a guanine nucleotide in the $2 \mathrm{G}$ allele of the MMP-1 $-16071 \mathrm{G} / 2 \mathrm{G}$ polymorphism creates a core binding site for transcription factor Ets, leading to a significantly higher promoter activity as reported by Ye et al [22]. MMP-1 SNPs have been correlated to the risk of BC [8], renal cell carcinoma [11], and colorectal cancer [12]. This study showed that the frequency of the $2 \mathrm{G}$ allele was significantly higher in BC patients compared to the controls ( $p=0.002$; OR 2.29), suggesting that variations in the $M M P-1$ promoter could facilitate bladder cancer formation and development. Our results were compatible to the study of Tasci et al. 2007 [23], who reported MMP1 2G allele to be significantly associated with the risk of BC. Hirata et al. [11] reported that the frequency of the $2 \mathrm{G} / 2 \mathrm{G}$ genotype was significantly higher in patients with RCC than in controls. Zhu et al. [24] also showed that there was a significant association between the $2 \mathrm{G} / 2 \mathrm{G}$ genotype and lung cancer risk.

Our results further showed that individuals with MMP-7 -181GG genotypes and $-181 \mathrm{G}$ allele were at significant increased risk of BC (p, 0.005; OR 2.38). The underlying mechanism for this association may be related to the promoter activity variation of the $181 \mathrm{G}$ 


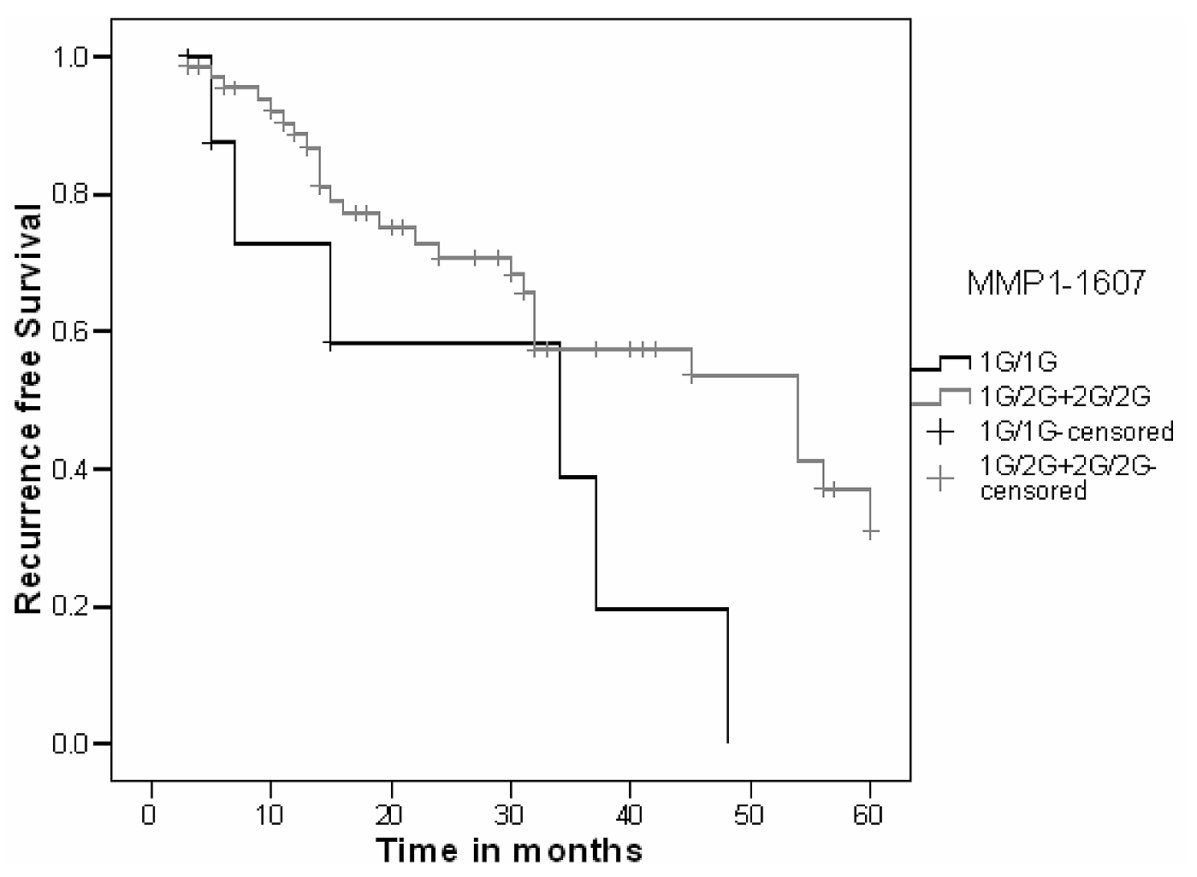

Fig. 2. Kaplan-Meier survival analysis for BCG treated BC patients in relation to $M M P 1-1607$ 1G/2G polymorphism, (Median recurrence free survival for $1 \mathrm{G} / 2 \mathrm{G}+2 \mathrm{G} / 2 \mathrm{G}=54$ months and $1 \mathrm{G} / 1 \mathrm{G}=34$ months, $\log$ rank $\mathrm{p}$ value $=0.030$ ).

alleles. Functional analysis revealed that MMP-7 $181 \mathrm{G}$ alleles can increase the gene transcription activity [14]. Previous studies have found that presence of $-181 \mathrm{G}$ variant allele results in higher level of $M M P-7$ expression [25]. Presence of high expression MMP-7 $-181 \mathrm{G}$ allele may alter cell surface signaling including cellular proliferation, invasion and apoptosis processes [26]. Therefore, individuals with excess $M M P-7$ activity by harboring the $-181 \mathrm{G}$ allele may be predisposed to malignant transformation. In addition, enhanced expression of $M M P-7$ due to $-181 \mathrm{G}$ allele may lead to increased activation of other members of the MMP family such as MMP-2. Association of MMP-7 $-181 \mathrm{G}$ allele with gastric ulcer, colorectal carcinoma, and ovarian cancer has also been reported [15,27,28].

Furthermore, association of the genotypes with disease stages was carried out to explore the influence of variant genotypes on disease phenotype. Our results indicated that $M M P 1$ and $M M P 7$ gene polymorphism are not implicated with any of the stages in bladder tumor.

Interaction of $M M P-1$ and $M M P-7$ genotypes with tobacco exposure to investigate the modulation of risk was also conducted, since tobacco exposure is a significant risk factor in BC [4]. Association of MMP polymorphism with tumor development in smokers has also been reported by Yu et al [29] in which an additive in- teraction between the $M M P-2$ promoter polymorphism and smoking on the risk of developing lung cancer had been demonstrated. As MMPs expression can be influenced by smoking [30], we hypothesized that individual with MMP higher promoter activity alleles may react more strongly in smokers than those with lower activities. In the present study we observed MMP1-1607 $2 \mathrm{G} / 2 \mathrm{G}$ and $M M P 7$ variant genotypes to be associated with high risk of $\mathrm{BC}$ among smokers. Given the small sample size in some strata and comparisons, these data need to be interpreted with caution, as it is possible that these results may have occurred due to chance.

Because individual polymorphisms are likely to confer modest effects to the risk of bladder cancer, we examined the effects of two MMP polymorphisms by performing haplotype analyses. Haplotype was constructed to analyze the association between the two polymorphic sites of $M M P 1$. Patients with haplotype G-2G carrying variant allele of $M M P 1-519 \mathrm{G}$ and $M M P 1-1607$ $2 \mathrm{G}$ were at higher risk $(P c=0.004)$. Additional research is required to investigate the functional effect of these haplotypes. Nevertheless, these results suggest that an appropriate combination of MMP-1 gene polymorphisms modifies the risk of overall bladder cancer.

We analyzed the association of MMP1-1607 polymorphism with risk of recurrence in NMIBC patients. The NMIBC patients were categorized on the basis of 
BCG treatment in BCG group and no BCG group. On comparison of the patients receiving BCG immunotherapy vs the patients with low grade tumors not on BCG, we observed a reduced risk for recurrence in $M M P 1$ $1 \mathrm{G} / 2 \mathrm{G}(\mathrm{HR}=0.28, p=0.017)$ and $1 \mathrm{G} / 2 \mathrm{G}+2 \mathrm{G} / 2 \mathrm{G}$ genotype $(\mathrm{HR}=0.39, p=0.039)$. Since reduced recurrence risk for BC patients on BCG immunotherapy was observed, Kaplan-Meier recurrence free survival analysis was conducted. The Kaplan-Meier analysis revealed that $1 \mathrm{G} / 1 \mathrm{G}$ genotype of $M M P 1-1607$ had a lower recurrence free survival of 34 months in comparison to 54 months for $1 \mathrm{G} / 2 \mathrm{G}+2 \mathrm{G} / 2 \mathrm{G}$ genotype (log rank $p=0.030$ ). These results clearly suggest that mutant $2 \mathrm{G}$ allele at -1607 might be responsible for the delay in recurrence of bladder tumor in patients on BCG immunotherapy perhaps due to therapeutic effect of BCG.

Limitations and sources of bias should be considered when performing the study. Case control studies are subject to selection bias and recall bias. The biological role for many of the MMPs in bladder epithelium and the functional effects for many of the SNPs are still unknown. Therefore, these novel findings require further research in larger studies.

In summary, genetic variations in the MMP family of -1607 2G allele and MMP7-181G carrier genotype with risk of UBC particularly in smokers may contribute to the development of bladder cancer. Haplotype combination of $\mathrm{G} / 2 \mathrm{G}$ projecting greater risk for $\mathrm{BC}$ and the variant allele of MMP1-1607 associated with delay in recurrence in BCG treated patients further project the significance of our study. These results, once validated, may help to identify high-risk populations as well as determine an individual's risk of invasive bladder cancer. Further study of the biological ramifications of these polymorphisms may add to our understanding of the biology of the disease and provide potential foci for targeted therapies.

\section{Acknowledgements}

The study was funded by Department of Science and Technology, New Delhi, Govt. of India. RG is thankful to Council of Scientific and Industrial Research for Senior Research Fellowship.

\section{References}

[1] D.M. Parkin, The global burden of urinary bladder cancer, Scand J Urol Nephrol Suppl 218 (2008), 12-20.
[2] W.J. Kim and S.C. Bae, Molecular biomarkers in urothelial bladder cancer, Cancer Sci 99 (2008), 646-652.

[3] Y. Shintani, Y. Sawada, T. Inagaki et al., Intravesical instillation therapy with bacillus Calmette-Guérin for superficial bladder cancer: study of the mechanism of bacillus CalmetteGuérin immunotherapy, Int J Urol 14 (2007), 140-146.

[4] F. Levi, Cancer prevention: epidemiology and perspectives, Eur J Cancer 35 (1999), 1912-1924.

[5] A. Tardon, W.J. Lee, M. Delgado-Rodriguez et al., Leisuretime physical activity and lung cancer: a meta-analysis, Cancer Causes Control 16 (2005), 389-397.

[6] S. Ye, Influence of matrix metalloproteinase genotype on cardiovascular disease susceptibility and outcome, Cardiovasc Res 69 (2006), 636-645.

[7] P. O-charoenrat, P. Leksrisakul and S. Sangruchi, A functional polymorphism in the matrix metalloproteinase-1 gene promoter is associated with susceptibility and aggressiveness of head and neck cancer, Int J Cancer 118 (2006), 2548-2553.

[8] A.K. Kader, J. Liu, L. Shao et al., Matrix metalloproteinase polymorphisms are associated with bladder cancer invasiveness, Clin Cancer Res 13 (2007), 2614-2620.

[9] T. Fujimoto, S. Parry, M. Urbanek, M. Sammel et al., A single nucleotide polymorphism in the matrix metalloproteinase-1 (MMP-1) promoter influences amnion cell MMP-1 expression and risk for preterm premature rupture of the fetal membranes, J Biol Chem 277 (2002), 6296-6302.

[10] Z. Cao, C. Li, L. Jin and E.F. Corbet, Association of matrix metalloproteinase-1 promoter polymorphism with generalized aggressive periodontitis in a Chinese population, J Periodontal Res 40 (2005), 427-431.

[11] H. Hirata, K. Naito, S. Yoshihiro et al., A single nucleotide polymorphism in the matrix metalloproteinase-1 promoter is associated with conventional renal cell carcinoma, Int J Cancer 106 (2003), 372-374.

[12] F. Zinzindohoué, T. Lecomte, J.M. Ferraz et al., Prognostic significance of MMP-1 and MMP-3 functional promoter polymorphisms in colorectal cancer, Clin Cancer Res 11 (2005), 594-599.

[13] L. Six, C. Grimm, S. Leodolter et al., A polymorphism in the matrix metalloproteinase-1 gene promoter is associated with the prognosis of patients with ovarian cancer, Gynecol Oncol 100 (2006), 506-510.

[14] S. Jormsjö, C. Whatling, D.H. Walter et al., Allele-specific regulation of matrix metalloproteinase-7 promoter activity is associated with coronary artery luminal dimensions among hypercholesterolemic patients, Arterioscler Thromb Vasc Biol 21 (2001), 1834-1839.

[15] J. Zhang, X. Jin, S. Fang et al., The functional polymorphism in the matrix metalloproteinase-7 promoter increases susceptibility to esophageal squamous cell carcinoma, gastric cardiac adenocarcinoma and non-small cell lung carcinoma, Carcinogenesis 26 (2005), 1748-1753.

[16] M. Colombel, M. Soloway and H. Akaza, Epidemiology, Staging, Grading and risk stratification of bladder cancer, Euro Urol Suppl 7 (2008), 618-626.

[17] S.A. Miller, D.D. Dykes and H.F. Polesky, A simple salting out procedure for extractingDNA from human nucleated cells, Nucleic Acids Res 16 (1988), 1215.

[18] M. Jurajda, J. Muzík, L. Izakovicová Hollá and J. Vácha, A newly identified single nucleotide polymorphism in the promoter of the matrix metalloproteinase-1 gene, Mol Cell Probes 16 (2002), 63-66.

[19] M. Bjorklund and E. Koivunen, Gelatinase-mediated migration and invasion of cancer cells, Biochim Biophys Acta 1755 
(2005), 37-69

[20] W.G. Stetler-Stevenson, L.A. Liotta and D.E. Kleiner, Extracellular matrix 6: role of matrix metalloproteinases in tumor Invasion and metastasis, FASEB J 7 (1993), 1434-1441.

[21] Y. Kanamori, M. Matsushima, T. Minaguchi et al., Correlation between expression of the matrix metalloproteinase-1 gene in ovarian cancers and insertion/deletion polymorphism in its promoter region, Cancer Res 5 (1999), 4225-4227.

[22] S. Ye, P. Eriksson, A. Hamsten et al., Progression of coronary atherosclerosis is associated with a common genetic variant of the human stromelysin-1 promoter which results in reduced gene expression, J Biol Chem 271 (1996), 13055-13060.

[23] A.I. Tasci, V. Tugcu, E. Ozbek et al., A single-nucleotide polymorphism in the matrix metalloproteinase-1 promoter enhances bladder cancer susceptibility, BJU Int 101 (2008), 503 507.

[24] Y. Zhu, M.R. Spitz, L. Lei et al., A single nucleotide polymorphism in the matrix metalloproteinase-1 promoter enhances lung cancer susceptibility, Cancer Res 61 (2001), 7825-7829.

[25] U.K. Saarialho-Kere, E.C. Crouch and W.C. Parks, Matrix metalloproteinase matrilysin is constitutively expressed in adult human exocrine epithelium, J Invest Dermatol 105 (1995), 190-196
[26] W.H. Yu, J.F. Woessner, Jr., J.D. McNeish et al., CD44 anchors the assembly of matrilysin/MMP-7 with heparin-binding epidermal growth factor precursor and ErbB4 and regulates female reproductive organ remodeling, Genes Dev 16 (2002), 307-323.

[27] G. Ghilardi, M.L. Biondi, M. Erario et al., Colorectal carcinoma susceptibility and metastases are associated with matrix metalloproteinase-7 promoter polymorphisms, Clin Chem 49 (2003), 1940-1942.

[28] Y. Li, X. Jin, S. Kang et al., Polymorphisms in the promoter regions of the matrix metalloproteinases-1, -3, -7, and -9 and the risk of epithelial ovarian cancer in China, Gynecol Oncol 101 (2006), 92-96.

[29] C. Yu, K. Pan, D. Xing et al, Correlation between asingle nucleotide polymorphism in the matrix metalloproteinase-2 promoter and risk of lung cancer, Cancer Res 62 (2002), 64306433.

[30] C. Lahmann, J. Bergemann, G. Harrison et al., Matrix metalloproteinase-1 and skin ageing in smokers, Lancet 357 (2001), 935-936. 


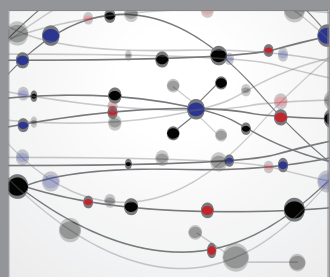

The Scientific World Journal
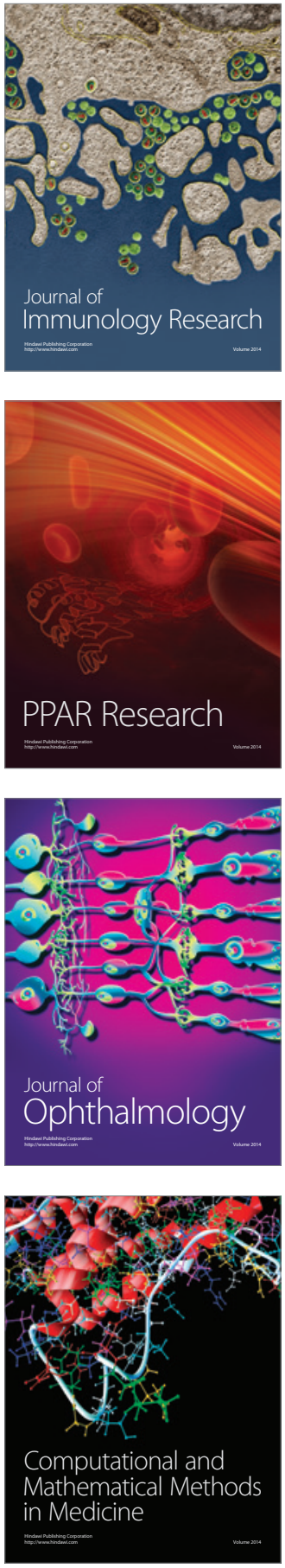

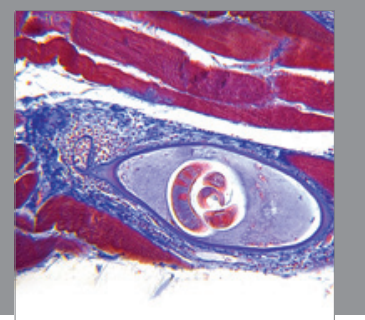

Gastroenterology

Research and Practice
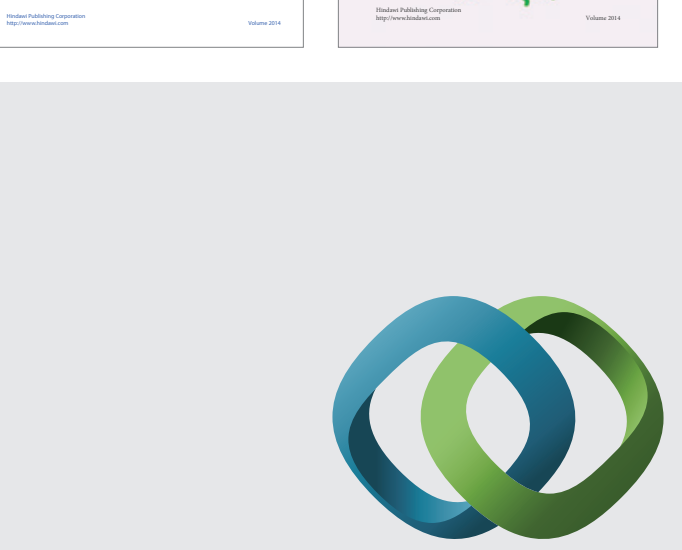

\section{Hindawi}

Submit your manuscripts at

http://www.hindawi.com
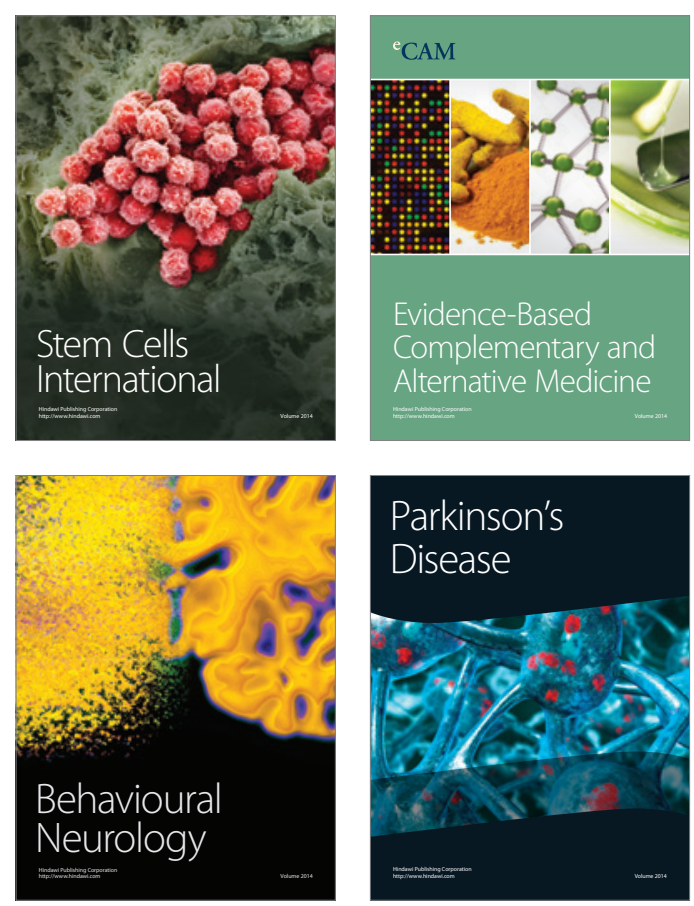

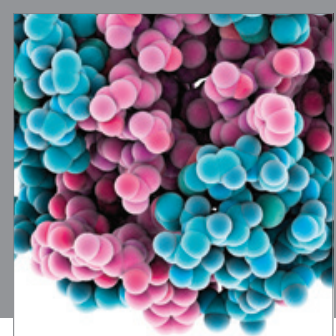

Journal of
Diabetes Research

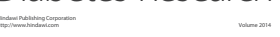

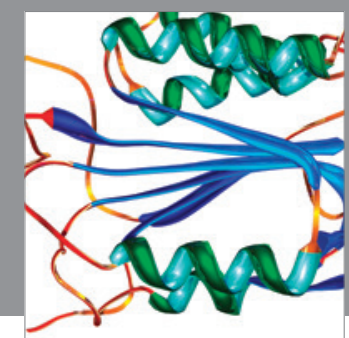

Disease Markers
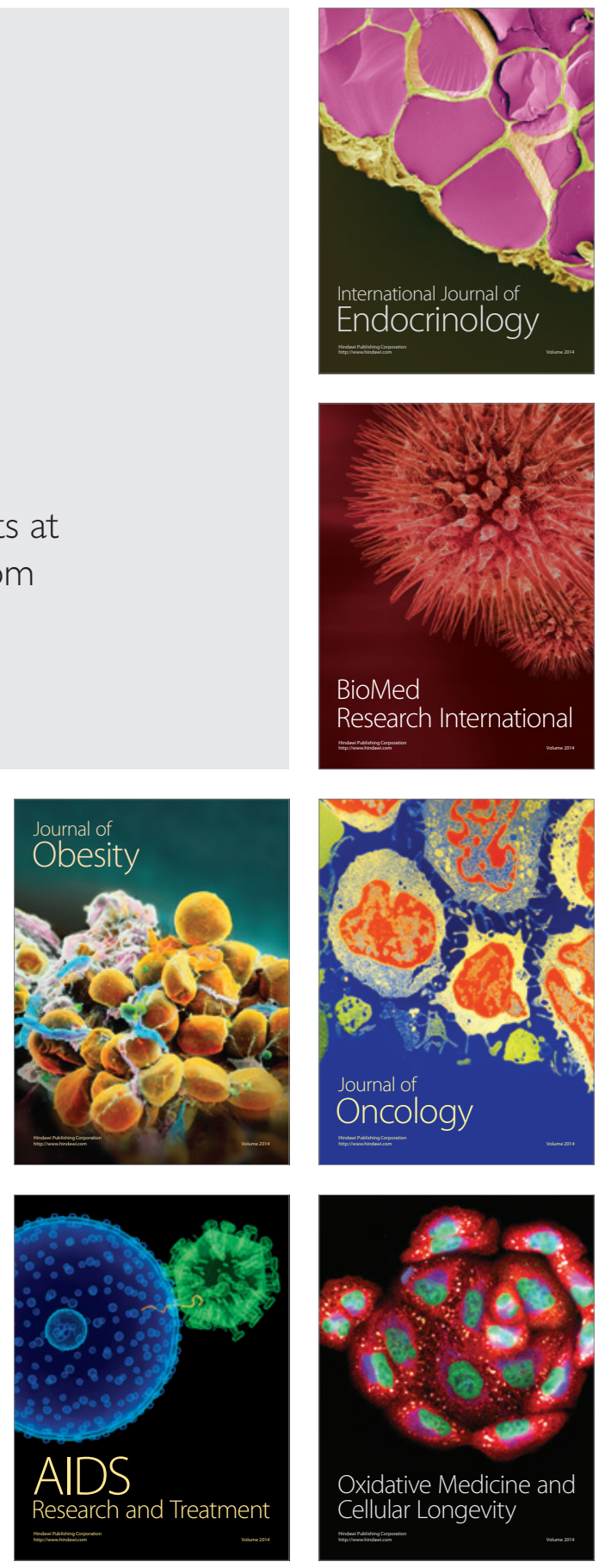